\title{
The Effect of Postoperative Pain Treatment on the Incidence of Anastomotic Insufficiency after Rectal and Rectosigmoideal Surgery
}

\section{Adámek S. ${ }^{1}$, Matoušková $0 .{ }^{2}$, Polanecký O. ${ }^{1}$, Světlík S. ${ }^{2}$, Skořepa J. ${ }^{1}$, Šnajdauf M. ${ }^{1}$}

13rd Department of Surgery, First Faculty of Medicine, Charles University in Prague and University Hospital Motol, Prague, Czech Republic; 2Institute of Pharmacology, First Faculty of Medicine, Charles University in Prague and General University Hospital in Prague, Prague, Czech Republic

Received July 9, 2013; Accepted November 25, 2013.

Key words: Rectal and rectosigmoideal surgery - Postoperative pain - Sufentanil Anastomotic insufficiency

Abstract: The aim of prospective study was to evaluate the pain relief in the postoperative period and consumption of opioid and non-opioid analgesics as a risk factor of the anastomotic insufficiency after rectal and rectosigmoideal resection for carcinoma. Anastomotic insufficiency is one of the most feared and life threatening early complications. No articles about the effect of the response to opioid therapy in the postoperative period on the risk of this major clinical problem have been published. We compared the effect of opioid and non-opioid analgesics in 109 patients who underwent rectal and rectosigmoideal resection in a prospective study. We evaluated the appearance of anastomotic insufficiency and clinical conditions in the relationship with the pain relief in the postoperative period and consumption of opioid and non-opioid analgesics. The pain intensity and the consumption of analgesics were significantly increased in the group of nonresponders. The rate of PONV (postoperative nausea and vomiting) in the responders and nonresponders groups was $69 \%$ and $78 \%$, respectively. However, the differences did not reach significant level. Other clinical conditions were not significantly different between the both groups, too. The difference in the incidence of anastomotic insufficiency between both groups was highly significant, $6 \%$ cases of anastomotic insufficiency in the responders group and $19 \%$ in nonresponders group $\left(\chi^{2}=7.73 ; p=0.0054\right)$. Nonrespoders to opioid therapy and their high consumption of second-line analgesics is a high risk factor for anastomotic insufficiency.

This study was supported by Charles University project PRVOUK P25/LF1/2.

Mailing Address: Olga Matoušková, MD., PhD., Institute of Pharmacology, First Faculty of Medicine, Charles University in Prague and General University Hospital in Prague, Albertov 4, 12800 Prague 2, Czech Republic; Phone: +420 224968 030; Fax: +420 224968 149; e-mail: olga.matouskova@If1.cuni.cz 


\section{Introduction}

Postoperative pain is a model example of acute pain in terms of pathophysiology and therapeutic. The surgical procedure leads to local tissue damage, resulting in the release of prostaglandins, histamine, serotonin, bradykinin and other inflammatory mediators. The surgery procedures also generates harmful stimuli, irritates the free nerve endings and nociceptors (Šerý et al., 2005). Adequate treatment of postoperative pain leads to a reduction of postoperative morbidity and to the shorter length of hospitalization. For the treatment of postoperative pain opioid analgesics, non-opioid analgesics and analgesic combinations of both groups are used. Typical changes related to the administration of opioids are nausea and vomiting. In patients after rectal and rectosigmoideal resection, the especially undesirable effect is the hypomotility to paralysis of the colon (Chappell et al., 2008). The above-mentioned pathophysiological changes following rectal and rectosigmoideal resection and the hypomotility to paralysis of colon after administration of opioids increases the risk of anastomotic insufficiency. Anastomotic insufficiency is one of the most feared and life threatening early complications following rectal anastomotic and continues to represent a major clinical problem. The reported clinical insufficiency rate after rectal and rectosigmoideal resection for cancer varies from $3 \%$ to $21 \%$ and generally results in an important increase of postoperative morbidity (Kanellos et al., 2004). Male gender, obesity, level of anastomosis and high blood loss during surgery increase the risk of anastomotic insufficiency (Law et al., 2000; Cong et al., 2009; Lee, 2009). Many studies describe the degree of the response to opioid therapy and presence of constipation, nausea, vomiting and sedation (Zenz et al., 1992; Huse et al., 2001; Trescot et al., 2008). No articles about the effect of the response to opioid therapy in the postoperative period on the risk of this major clinical problem have been published. Our primary objective was to evaluate the pain relief in the postoperative period and consumption of opioid and nonopioid analgesics as a risk factor of the anastomotic insufficiency after rectal and rectosigmoideal resection for carcinoma. The secondary objective was to describe the effect of pain relief on the appearance of postoperative nausea and vomiting (PONV), first stool passage and length of hospitalization.

\section{Material and Methods}

Patients

Totally 109 patients hospitalized in the years 2011-2012 at the $3^{\text {rd }}$ Department of Surgery, First Faculty of Medicine, Charles University in Prague and University Hospital Motol, who underwent rectal and rectosigmoideal resection were included in the prospective study. All patients had preoperative endoscopy with histologically proven adenocarcinoma. All patients signed the informed consent before participation. The study was approved by the local Ethics Committee and it was conducted in accordance with the Declaration of Helsinki. Reasons for 
exclusion from the study were allergy to opioids, unwillingness to cooperate in the evaluation of pain, adverse effects and disagreement patient, and the administration of non-steroidal anti-inflammatory analgesics and/or opioids one week before the surgery. The patients in whom a protective ileostomy was carried out during the original operation were excluded from this investigation, too.

\section{Surgical procedure}

For premedication diazepam was administered per os. The day before operation, bowel lavage with 3 litres of macrogolum was carried out. Antibiotic prophylaxis ( $3 \mathrm{~g}$ ampicillin and $0.5 \mathrm{~g}$ metronidazole) was administered at the time of induction of anaesthesia. Another two doses of this antibiotic prophylaxis were administered within 12 hours after surgery. All patients underwent surgery under general anaesthesia, based on a combination of propofol $(2 \mathrm{mg} / \mathrm{kg})$ and sufentanil $(2 \mu \mathrm{g} / \mathrm{kg})$ and were operated by the professor Adámek's surgical team. Rectal and rectosigmoideal resection was performed using a combination of linear and circular staplers. After completion of the anastomosis, its integrity was tested by administration of $100 \mathrm{ml}$ of $10 \%$ iodopovidone in the transanal enema. Liquid diet began at the second postoperative day; normal diet began at the fourth postoperative day. The drain placed in the true pelvis was removed during the third postoperative day. The length of hospitalization, first stool passage and incidence of anastomotic insufficiency were assessed.

\section{Postoperative pain treatment}

After returning from the surgery, the postoperative pains in patients were treated with epidural sufentanil analgesia $(100-150 \mu g / d a y)$. Continuous infusion epidural analgesia was supplemented with $50 \mathrm{mg}$ bupivacaine. Second-line treatment of pain was based on the combination of non-steroidal anti-inflammatory drug and opioid analgetic according to the requirement of patient. Anatomical therapeutic chemical/defined daily doses (ATC/DDD) methodology was used to assess the drug consumption. Pain intensity was assessed using visual analogue scale (VAS 0-100 mm) at 1, 2, 3, 4, 5, 6, 12, 24, 36 and 48 hours after the surgery. In addition, patient's satisfaction with pain management and appearance of PONV were assessed.

\section{Definition of anastomotic insufficiency and treatment}

An anastomotic insufficiency was considered to be present when patient developed either pelvic pain, fever, leukocytosis or increased serum concentrations of C-reactive protein (CRP) and/or procalcitonin. Feculent substances from the pelvic drain indicated anastomotic insufficiency. The diagnosis was verified by computed tomography (CT) of the abdomen and pelvis with rectal contrast enema, contrast enema radiography alone. Anastomotic insufficiencies were classified as major and minor insufficiency. Major insufficiency was defined as peritonitis and septicemia due to insufficiency, or a necessary surgical intervention in the case of broad 
insufficiency. Minor insufficiency (a small amount of extravasation accompanied by less dramatic clinical signs and no signs of sepsis) was treated by endoscopically controlled daily transanal lavage. All patients with anastomotic insufficiency received parenteral antibiotic therapy for a minimum of 5 days.

Statistical analysis

Data are reported as mean \pm standard deviation. For statistical evaluation we used $\chi^{2}$, Mann-Whitney test and Wilcoxon test for two dependent variables $(p<0.05)$.

\section{Results}

Patients

We tested all patients using pain relief on visual analogue scale for responder $(n=63)$ and nonresponder $(n=46)$ to opioid therapy in the first six hours after surgery. Patients were divided according to the consumption of analgesics required to pain relief greater than $50 \%$. Responders required only epidural sufentanil analgesia, whereas nonresponders required administration of non-opioid analgesics to pain relief greater than $50 \%$. Demographic characteristics as well as length or duration of anaesthesia were not significantly different between the responders and nonresponders groups (Table 1).

\section{Table 1 - Basic characteristics of both groups of patients}

\begin{tabular}{lccc}
\hline & $\begin{array}{c}\text { Responders to } \\
\text { opioid therapy } \\
(\mathrm{n}=63)\end{array}$ & $\begin{array}{c}\text { Nonresponders to } \\
\text { opioid therapy } \\
(\mathrm{n}=46)\end{array}$ & P-value \\
\hline Age (years) & $68.33 \pm 11.57$ & $62.84 \pm 12.52$ & $\mathrm{NS}$ \\
\hline $\mathrm{BMI}\left(\mathrm{kg} / \mathrm{m}^{2}\right)$ & $25.87 \pm 3.919$ & $26.86 \pm 3.72$ & $\mathrm{NS}$ \\
\hline $\begin{array}{l}\text { Gender } \\
\text { (male/female) }\end{array}$ & $37 / 26$ & $30 / 16$ & $\mathrm{NS}$ \\
\hline $\begin{array}{l}\text { Length of operation } \\
\text { (min) }\end{array}$ & $123.71 \pm 41.27$ & $119.67 \pm 72.76$ & $\mathrm{NS}$ \\
\hline $\begin{array}{l}\text { ASA grade } \\
\text { I-II/III-IV }\end{array}$ & $34 / 29$ & $29 / 17$ & $\mathrm{NS}$ \\
\hline
\end{tabular}

Data are reported as mean \pm SD; NS - non-significant; BMI - body mass index; ASA - assessing the fitness of patients before surgery (American Society of Anesthesiologists)

Anastomotic insufficiency

Of the total 109 patients anastomotic insufficiency was present in 13 cases (11.9\%). Postoperative lethality was $7.69 \%$ in the patients with anastomotic insufficiency and $1.04 \%$ in the patients without anastomotic insufficiency $\left(\chi^{2}=4.69 ; p=0.0304\right)$. The total postoperative lethality was $1.8 \%$. Male gender is high-risk factor for 
anastomotic insufficiency after rectal and rectosigmoideal resection in the comparison with patients without anastomotic insufficiency, $77 \%$ and $57 \%$, respectively $\left(\chi^{2}=5.93 ; p=0.01\right)$. Pain intensity 6 hours after surgery was $47.38 \pm 10.45 \mathrm{~mm}$ in the patients with anastomotic insufficiency and $17.40 \pm 16.85 \mathrm{~mm}$ in the patients without anastomotic insufficiency $(p=0.0000)$.

Anastomotic insufficiency and postoperative pain treatment

The pain intensity 6,12, 24 and 48 hours after surgery and the number of defined daily doses (DDD) of non-opioid and summary second-line analgesics were significantly increased in the group of nonresponders. The rate of PONV in the responders and nonresponders groups was $69 \%$ and $78 \%$, respectively. However, the differences did not reach significant value. The first stool passage and the length of hospitalization were not significantly different in both compared groups. Table 2 describes pain relief, second-line analgetics and the basic

\section{Table 2 - Characteristics of clinical condition and second-line analgesics of both groups of patients}

\begin{tabular}{|c|c|c|c|}
\hline & $\begin{array}{l}\text { Responders } \\
\text { to opioid therapy } \\
(n=63)\end{array}$ & $\begin{array}{l}\text { Nonresponders } \\
\text { to opioid therapy } \\
(n=46)\end{array}$ & P-value \\
\hline Initial pain (mm) & $27.25 \pm 23.55$ & $38.91 \pm 22.56$ & 0.0130 \\
\hline $\begin{array}{l}\text { Pain intensity } 6 \text { hours after } \\
\text { surgery }(\mathrm{mm})\end{array}$ & $7.14 \pm 13.37$ & $34.13 \pm 22.95$ & 0.0000 \\
\hline $\begin{array}{l}\text { Pain intensity } 12 \text { hours after } \\
\text { surgery }(\mathrm{mm})\end{array}$ & $4.28 \pm 12.27$ & $8.26 \pm 14.03$ & 0.011 \\
\hline $\begin{array}{l}\text { Pain intensity } 24 \text { hours after } \\
\text { surgery }(\mathrm{mm})\end{array}$ & $3.96 \pm 9.76$ & $16.52 \pm 16.89$ & 0.0000 \\
\hline $\begin{array}{l}\text { Pain intensity } 48 \text { hours after } \\
\text { surgery }(\mathrm{mm})\end{array}$ & $2.85 \pm 7.05$ & $14.13 \pm 15.71$ & 0.0000 \\
\hline $\begin{array}{l}\text { Second-line analgesics and } \\
\text { defined daily doses (DDD) } \\
\text { - only non opioid analgesics }\end{array}$ & $1.054 \pm 0.885$ & $1.913 \pm 0.695$ & 0.0000 \\
\hline $\begin{array}{l}\text { Second-line analgesics } \\
\text { and defined daily doses } \\
\text { (DDD) - summary }\end{array}$ & $1.363 \pm 0.916$ & $2.440 \pm 0.908$ & 0.0000 \\
\hline PONV (yes/no) & $44 / 19$ & $36 / 10$ & NS \\
\hline First stool passage (day) & $4.42 \pm 1.77$ & $4.80 \pm 2.07$ & NS \\
\hline Length of hospitalization (day) & $11.87 \pm 4.89$ & $12.74 \pm 5.47$ & NS \\
\hline
\end{tabular}

Data are reported as mean \pm SD; NS - non-significant; PONV - postoperative nausea and vomiting 
characteristics of clinical condition in the responders and nonresponders groups. Postoperative lethality was $1.58 \%$ in the group of responders, in the group of nonresponders $2.08 \%$. The difference between both groups was not significant. The difference in the incidence of anastomotic insufficiency between both groups was highly significant, $6.35 \%$ cases of anastomotic insufficiency in the responders group and $19.57 \%$ in nonresponders group $\left(\chi^{2}=7.73 ; p=0.0054\right)$.

\section{Discussion}

Similarly to other papers, our study describes that male gender is a risk factor for anastomotic insufficiency (Law et al., 2000; Cong et al., 2009; Lee, 2009). Unfortunately, in our study, we found that obesity was not a risk factor. Moreover, analysis of our results confirmed that high consumption of opioid and non-opioid analgesics and pain relief smaller than $50 \%$ in the first six hours after surgery are a high risk factor for anastomotic insufficiency. It can be concluded that high or increasing pain intensity is an early indicator for the prevention and diagnosis of anastomotic insufficiency. In addition, early diagnosis of anastomotic insufficiency and urgent therapeutic intervention are required to avert life threatening conditions. The usual presentation of anastomotic insufficiency is unexplained pyrexia often with tachycardia (Alberts et al., 2003). Unfortunately, we do not know the reason for such large differences in pain intensity after administration of approximately the same doses of sufentanil. One of the causes of those life threatening complications could be genetic predisposition. Sufentanil has high affinity to the $\mu$-opioid receptor 1 (OPRM1) by a polymorphic gene (Landau et al., 2008; Tan et al., 2009). These works describe higher pain intensity, higher opioid consumption and higher rate of adverse effects in patients with genotype OPRM $118 \mathrm{G} / \mathrm{G}$ than in individuals carrying the allele OPRM 118A. With regard to the mechanism of action it can be assumed that the $\mu$-receptor genotype may also influence the pharmacotherapeutic effect of sufentanil. Genetic polymorphism is described also for the transporter systems such as P-glycoprotein expression product of the multidrug resistance gene 1 (MDR1), which is involved in the transport of opioids. MDR1 gene in the Czech population is highly polymorphic (Pechandová et al., 2006). Polymorphism MDR1 transporter activity may alter P-glycoprotein substrates and thereby thus indirectly affect the pharmacodynamics of sufentanil, in a concentration-dependent effect. Study by Terao et al. (1996) confirmed the expression of P-glycoprotein in the brain. Studies describe the effect of common functional genetic polymorphism catechol-O-metyltransferasy (COMT) affecting the metabolism of catecholamines in response to opioid therapy in humans. In patients with genotype met/met smaller pain relief was observed and smaller consumption of opioid in the comparison to genotypes val/met and val/val. In patients with the variant allele val158, higher sensory and affective ratings of pain and more negative internal emotional state was observed (Diatchenko et al., 2005; Reyes-Gibby et al., 2007; Rakvåg et al., 2008). Most operations are 
planned; this fact gives hope for the assessment of genetic predisposition before surgery. White (2005) and White et al. (2007) described the use of non-opioid analgesics e.g., local anesthetics, non-steroidal anti-inflammatory drugs (NSAIDs), cyclooxygenase-2 (COX-2) inhibitors, acetaminophen, ketamine, alpha 2-agonists. Dauri et al. (2009) published in his article that gabapentin and pregabalin reduce pain and opioid consumption after surgery in confront with placebo. Many other studies described the treatment of postoperative therapy in opioid tolerant patients by non-opioids analgesics (Jarzyna, 2005; Bourne, 2008; Urban et al., 2008). Paracetamol is often given after major surgery. There was a significant reduction in pain, opioid consumption and PONV (Kvalsvik et al., 2003). Those studies suggest a potential alternative therapy of acute postoperative pain in patients with genetic predisposition of nonresponse to opioid therapy. In the future it is expected that assessment of genetic predisposition of patients before surgery can reduce the occurrence of anastomotic insufficiency and postoperative morbidity and lethality.

\section{Conclusion}

Nonrespoders to opioid therapy and high consumption of second-line analgesics is a high risk factor for anastomotic insufficiency. In the future it is expected that assessment of genetic predisposition of patients before surgery can reduce the occurrence of anastomotic insufficiency and postoperative morbidity and lethality.

\section{References}

Alberts, J. C., Parvaiz, A., Moran, B. J. (2003) Predicting risk and diminishing the consequences of anastomotic dehiscence following rectal resection. Colorectal Dis. 5(5), 478-482.

Bourne, N. (2008) Managing acute pain in opioid tolerant patients. J. Perioper. Pract. 18(11), 498-503.

Chappell, D., Rehm, M., Conzen, P. (2008) Methylnaltrexone for opioid-induced constipation in advanced illness. N. Engl. J. Med. 359(10), 1071.

Cong, Z. J., Fu, C. G., Wang, H. T., Liu, L. J., Zhang, W., Wang, H. (2009) Influencing factors of symptomatic anastomotic leakage after anterior resection of the rectum for cancer. World J. Surg. 33(6), 1292-1297.

Dauri, M., Faria, S., Gatti, A., Celidonio, L., Carpenedo, R., Sabato, A. F. (2009) Gabapentin and pregabalin for the acute post-operative pain management. A systematic-narrative review of the recent clinical evidences. Curr. Drug Targets 10(8), 716-733.

Diatchenko, L., Slade, G. D., Nackley, A. G., Bhalang, K., Sigurdsson, A., Belfer, I., Goldman, D., Xu, K., Shabalina, S. A., Shagin, D., Max, M. B., Makarov, S. S., Maixner, W. (2005) Genetic basis for individual variations in pain perception and the development of a chronic pain condition. Hum. Mol. Genet. 14(1), 135-143.

Huse, E., Larbig, W., Flor, H., Birbaumer, N. (2001) The effect of opioids on phantom limb pain and cortical reorganization. Pain 90(1-2), 47-55.

Jarzyna, D. (2005) Opioid tolerance: a perioperative nursing challenge. Medsurg. Nurs. 14(6), 371-376.

Kanellos, I., Vasiliadis, K., Angelopoulos, S., Tsachalis, T., Pramateftakis, M. G., Mantzoros, I., Betsis, D. (2004) Anastomotic leakage following anterior resection for rectal cancer. Tech. Coloproctol. 8, s79-s81 (Suppl. 1).

Kvalsvik, O., Borchgrevink, P. C., Hagen, L., Dale, O. (2003) Randomized, double-blind, placebocontrolled study of the effect of rectal paracetamol on morphine consumption after abdominal hysterectomy. Acta Anaesthesiol. Scand. 47(4), 451-456.

Landau, R., Kern, C., Columb, M. O., Smiley, R. M., Blouin, J. L. (2008) Genetic variability of the mu-opioid 
receptor influences intrathecal fentanyl analgesia requirements in laboring women. Pain 39(1), 5-14.

Law, W. I., Chu, K. W., Ho, J. W., Chan, C. W. (2000) Risk factors for anastomotic leakage after low anterior resection with total mesorectal excision. Am. J. Surg. 179(2), 92-96.

Lee, L. (2009) Risk factors for anastomotic leakage after resection for rectal cancer. Am. J. Surg. 198(3), 461.

Pechandová, K., Buzková, H., Slanař, O., Perlík, F. (2006) Polymorphisms of the MDR1 gene in the Czech population. Folia Biol. (Praha) 52(6), 184-189.

Rakvåg, T. T., Ross, J. R., Sato, H., Skorpen, F., Kaasa, S., Klepstad, P. (2008) Genetic variation in the catechol-Omethyltransferase (COMT) gene and morphine requirements in cancer patients with pain. Mol. Pain 4, 64.

Reyes-Gibby, C. C., Shete, S., Rakvåg, T., Bhat, S. V., Skorpen, F., Bruera, E., Kaasa, S., Klepstad, P. (2007) Exploring joint effects of genes and the clinical efficacy of morphine for cancer pain: OPRM1 and COMT gene. Pain 130(1-2), 25-30.

Šerý, O., Hrazdilová, O., Matalová, E., Ševčík, P. (2005) Pain research update from a genetic point of view. Pain Pract. 5(4), 341-348.

Tan, E. C., Lim, E. C., Teo, Y. Y., Lim, Y., Law, H. Y., Sia, A. T. (2009) Ethnicity and OPRM variant independently predict pain perception and patient-controlled analgesia usage for post-operative pain. Mol. Pain 5, 32.

Terao, T., Hisanaga, E., Sai, Y., Tamai, I., Tsuji, A. (1996) Active secretion of drugs from the small intestinal epithelium in rats by P-glycoprotein functioning as an absorption barrier. J. Pharm. Pharmacol. 48(10), 1083-1089.

Trescot, A. M., Glaser, S. E., Hansen, H., Benyamin, R., Patel, S., Manchikanti, L. (2008) Effectiveness of opioids in the treatment of chronic non-cancer pain. Pain Physician 11, S181-S200 (2 Suppl.).

Urban, M. K., Ya Deau, J. T., Wukovits, B., Lipnitsky, J. Y. (2008) Ketamine as an adjunct to postoperative pain management in opioid tolerant patients after spinal fusions: a prospective randomized trial. HSS J. 4(1), 62-65.

White, P. F. (2005) The changing role of non-opioid analgesic techniques in the management of postoperative pain. Anesth. Analg. 101, S5-S22 (5 Suppl.).

White, P. F., Sacan, O., Tufanogullari, B., Eng, M., Nuangchamnong, N., Ogunnaike, B. (2007) Effect of short-term postoperative celecoxib administration on patient outcome after outpatient laparoscopic surgery. Can. J. Anaesth. 54(5), 342-348.

Zenz, M., Strumpf, M., Tryba, M. (1992) Long-term oral opioid therapy in patients with chronic nonmalignant pain. J. Pain Symptom Manage. 7(2), 69-77. 